\title{
Study on Construction of Performance Appraisal System for Railway Grass-roots Units Based on TQM
}

\author{
Yifan $\mathrm{LIU}^{\mathrm{a} *}$, Yingxia YUa , Zhihuan ZENG ${ }^{\mathrm{a}}$, Yun ZHANG \\ ${ }^{a}$ School of transportation and logistics, East China Jiaotong University, Jiangxi, Nanchang 330013, China \\ bZhengzhou Railway Bureau, Zhengzhou 450000, China
}

\begin{abstract}
This paper introduces methods of total quality management (TQM) to analyze and improve existing system of performance appraisal in railway grass-roots units. The improved system adopts process method to design overall structure and divides the performance assessment process into four stages with PDCA: performance plan, performance implementation, performance evaluation and performance application; then, evaluation index sub-system, monitoring subsystem, evaluation and improvement sub-system were designed. In the design process, this paper reflects the "three whole and one variety" idea of TQM, selects policy management as the theoretical basis of decomposing the Railway Bureau's fundamental objectives, employs tree diagram decomposition to set assessment indicators, and set evaluation criteria in accordance with principles of SMART. The experimental study shows that the new appraisal system can provides solutions to the existing problems and finds out the management direction, and also is the key point of sustainable development for Railways Bureau. Compared with the existing appraisal system of grassroots units, new system can get a better appraisal results, especially in appraisal system and task completion.
\end{abstract}

Keywords-TQM; Performance appraisal; The process method; PDCA; The railway grass-roots units

\section{INTRODUCTION}

At present, China's railways implement a three-tiered management system: the China Railway Companies, railway transportation companies and railway grass-roots units. Performance appraisal is the core of modern enterprise performance management [1]. It is obvious that applying performance appraisal to railway grass-roots units that only includes cost management can help railway bureau to guide its management direction and obtain key points, promote the sustainable development of Railway Bureau. Although current performance evaluation system of railway grass-roots units has been applied for many years and has achieved good effects, many problems and limitations still exist:

Firstly, while setting evaluation indicators and its weights, the former method is focused on financial indicators, which ignore process indicators and quality indicator. Meanwhile, the scope of evaluation indicators and relative weights are fuzzy.

Secondly, the evaluation methods need to be improved. Existing method involves few horizontal comparisons, which is based on historical data for vertical comparison. In addition, a comprehensive application of quantitative and qualitative

* Corresponding author. Tel.:18679959620

E-mail address:843804576@qq.com evaluation is deficient [2].

Thirdly, the incentive and restraint mechanism are worth optimizing, which didn't involve all staff. And the intensity of assessment is so small that assessment methods need to be improved.

Therefore, this paper explores a set of performance evaluation system for railway grass-roots units with TQM. Combined with traditional performance appraisal system, new system emphasizes horizontal function management, optimizes main process through applying "process method" and improves the coordination of horizontal management.

\section{OVERVIEW OF TOTAL QUALITY MANAGEMENT THEORY}

According to the definition of ISO 8402:1994, TQM is a management approach with quality-centered, on the basis of full participation, hoping to achieve long-term success through satisfying customers and all company members and benefit the society [3]. Experts put forward "three whole and one variety" ideas after years practice with TQM, namely, the quality management activity with whole process, all staff, all departments and multiple methods [4].

TQM theory advocates "process method" that refers to any activity, it converts input into output. The input resources include persons, facilities, work environments and information; any process can be divided into several smaller processes, and several similar processes can form a large process. The output turn to the input of next process and form a process chain. PDCA is the working procedure of TQM that is a dynamic improvement process, its process can be divided into four phases (plan, do, check, action [5]). The four phases are closely linked, which require recycling and improving continuously.

\section{CONSTRUCTION OF THE PERFORMANCE APPRAISAL SUB-SYSTEM FOR RAILWAY GRASS-ROOTS UNITS}

\section{A. Assessment System Design Issues}

While designing performance appraisal system, TQM is the starting point, performance appraisal process is the process of quality realization. According to "process method", the pattern of performance appraisal process method will be designed, see in Fig 1. In Fig 1, the entire process is the performance appraisal process, product refers to appraisal performance, customers and supplier are the Railway Bureau and grass-roots units, respectively, are the subject and object of performance 
appraisal. The output (customer satisfaction) refers to performance appraisal results. As a customer, Railway Bureau is the input of entire process, its demands are crucial. As a supplier, grass-roots units export performance to Railway
Bureau through performance appraisal process. In order to meet customer satisfaction, managers need to monitor and improve the whole process timely.

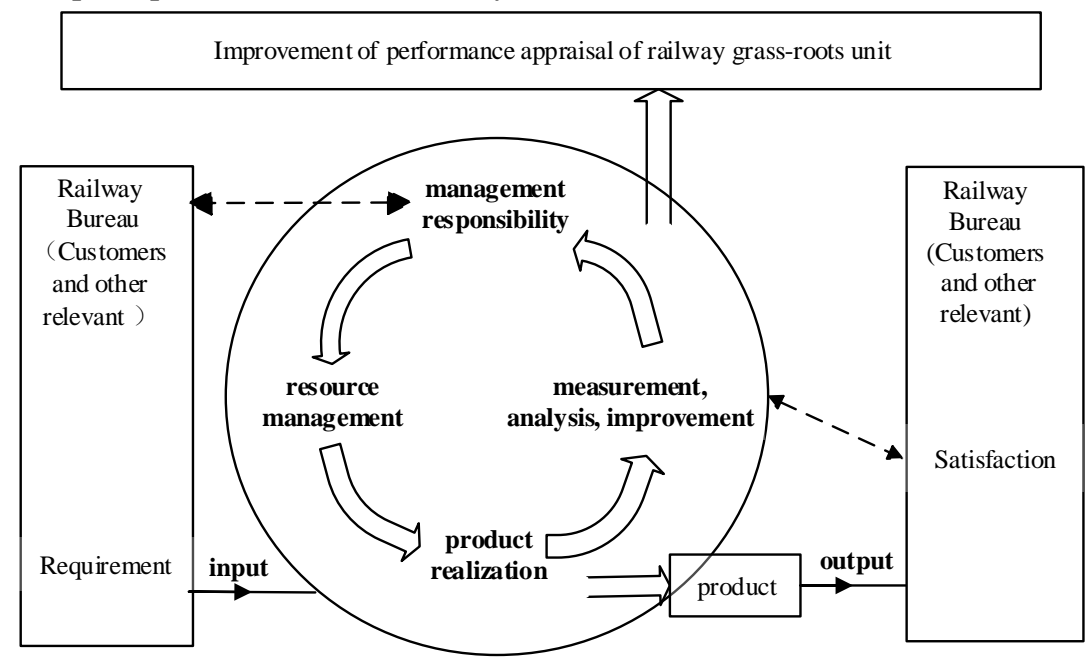

Fig. 1. Railway grass-roots unit performance appraisal process method pattern

On the basis of the performance appraisal process method pattern construction and other requirements of TQM, three aspects should be focused when designing the performance evaluation system:

\section{1) Applying the process methods to the overall design of} the assessment system

Designing the appraisal system based on PDCA and emphasizing process management, regarding performance evaluation as the whole of performance appraisal.

\section{2) Defining the purpose of assessment by identifying} customer needs

When applying TQM to design a performance assessment system, clarifying the needs of customers, that is, meeting the vision of Railway Bureau, realizing the preservation and appreciation of assets, and achieving sustainable development.
It's necessary to combine performance assessment with longterm strategic planning of Railway Bureau.

3) Reflecting the thinking of "three whole and one variety " in the assessment principle

Railway transport is a multi-system, multi-work, multilevel system, and no unit or employee can independently complete the production tasks. It's necessary to occupy a management thinking with integrating all staff, entire company, whole process, and multiple methods.

\section{B. PDCA Improves Performance Evaluation Process Design}

Starting with PDCA and concerns of system design, performance appraisal process is divided into four phases: performance planning, performance implementation, performance checking and performance acting. See in Fig 2.

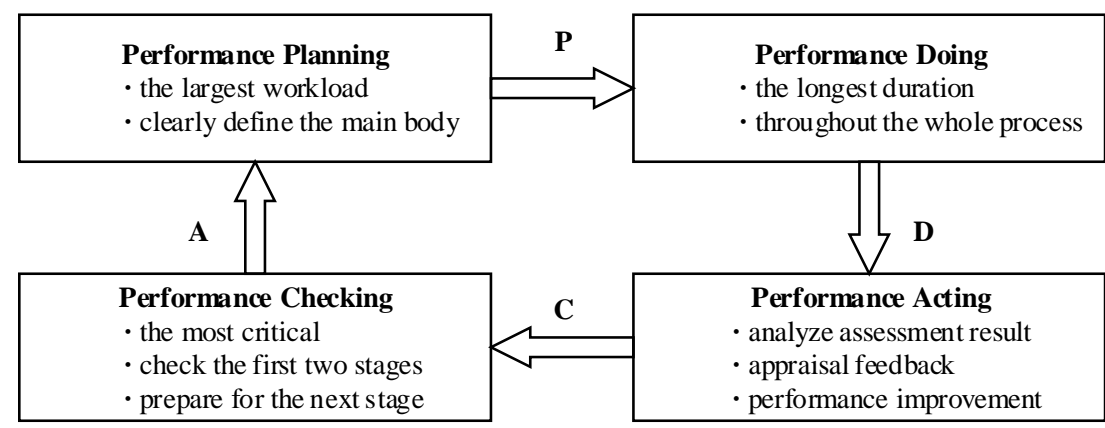

Fig. 2. Performance appraisal process

Through four stages of the performance appraisal process, accurate information reflecting objective reality can be obtained. And the design framework of performance appraisal system should include four major blocks:

- Performance evaluation index sub-system. On the basis of analyzing the subject and object of performance appraisal, setting assessment indicators and weight through decomposing assessment objectives.

- Performance monitoring sub-system. In accordance with the requirements of process method among process control, monitoring process in the stage of performance 
implementation, and timely improving performance when the abnormal trend happened.

- Performance measurement and evaluation sub-system. Analyzing requirements of process method, evaluation criteria for performance assessment can be clearly defined so that the assessment results can be obtained.

- Improvement of performance system. According to the results of performance evaluation, managers optimize and improve unit performance and assessment system.

\section{CONSTRUCTION OF PERFORMANCE EVALUATION SYSTEM FOR RAILWAY GRASS-ROOTS UNITS}

\section{A. Assessment Index System Construction}

1) Analyze the purpose of assessment and determine indicators

The purposes of assessment can be subdivided into four objectives under the principle of objective management. On those basis, tree diagram analysis method is used to classify Railway Bureau's demands. Next, assessment objectives, and performance evaluation indicators are refined and combed. As shown in Fig 3. The first level shows Railway Bureau's demands that also is the purpose of performance appraisal.

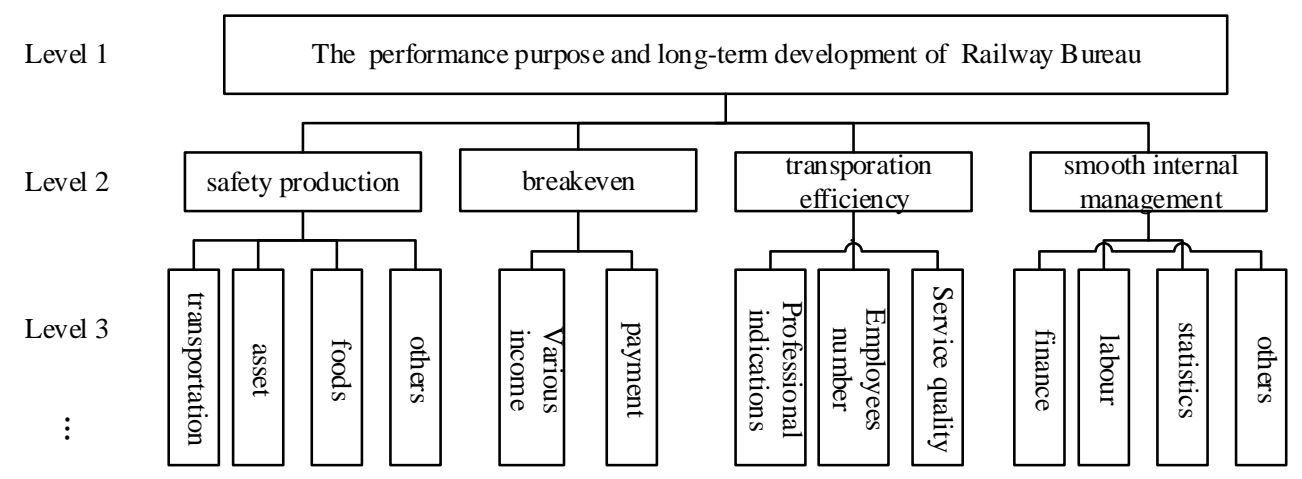

Fig. 3. Index decomposition tree

To further strengthen the operability of the assessment, all indicators can be sorted out and grouped into the first, second, and third-level indicators according to their character or commonness, availability and other attributes.

\section{2) Determination of Index Weights}

The weight of indicators can be determined by mixed methods with expert consultation, subjective experience. Experts will compare the importance of indicators that in same level. The higher degree of importance, the greater weight. And experts put forward the weight scheme based on the comparison results. Then, each department of the Railway Bureau starts brainstorming and revises the scheme from a professional perspective. After agreement is reached, the final weight of each assessment index can be determined.

\section{B. Performance Monitoring Sub-system Construction}

Monitoring sub-system is a guarantee means of achieving goals, which can promote performance, constrain and standardize entire performance evaluation process.

According to process method, monitoring sub-system must meet the following requirements: Transforming simple postexamination to the method that integrates pre-audit, intra-event control and post-examination, realizing full-process, alldirectional, normalized supervision among performance appraisal. Promoting the change of performance appraisal from static to dynamic and static, one-way feedback to multidirectional feedback, manual operation to network operation. Correcting the deviations in performance and achieving assessment information sharing in all departments.
Based on the requirements, the construction of monitoring sub-systems will start from the following five aspects: ensuring the main monitor body and giving power to the assessment team; implementing regular assessment and emphasizing performance process tracking; establishing smooth channel for performance information collection and building assessment information system; providing real-time dynamic assessment feedback, conducting timely and effective performance coaching to solve existing problem.

\section{Performance Measurement and Evaluation System Construction}

1) Standards and Target Value Setting

On the basis of performance appraisal indicators, the performance appraisal standards and target values must be determined before appraisal evaluation. So, standards and target values for the performance evaluation are designed in accordance with SMART principles (understandable, measurable, achievable, associable, and time-limited ${ }^{[6]}$ ).

\section{2) Evaluation Methods}

It is necessary to determine the appraisal method according to the indicators' characteristics, that is, to select appraisal methods according to the actual situation.

Quantitative evaluation. This method is mainly used for workload indicators that can be accurately measured by the values and associated with the whole business objectives.

Qualitative evaluation. Although some evaluation indicators can be clearly defined and be expressed specific behaviors, but cannot accurately measure the results of the 
indicators, nor can they set quantitative target values. It is necessary to use qualitative assessment methods.

One vote veto. The method is a special assessment criterion other than quantitative or qualitative assessment. Some events happened will be rejected directly, such as serious violations and traffic accidents, serious food poisoning incidents.

Process evaluation. In the assessment process, it is necessary to grasp the progress, dynamic data and carry out daily evaluation for promoting a good result.

\section{Performance Improvement Sub-system}

The contents of performance improvement include: performance diagnosis and development, implementation and evaluation of improvement plans. Two objects for performance improvement: grassroots unit performance and performance appraisal system. According to contents and objects, the specific work of improvement is mainly reflected in the following two aspects:

For the grass-roots units: According to the results of performance monitoring and evaluation, managers conduct a full-process diagnosis of grass-roots units, analyze the commonalities and personality causes affecting the performance level, and put forward suggestions.
For the performance appraisal system: Managers take a full-process diagnosis which aim at the deviations and problems encountered in application of appraisal system, including: whether the assessment index system is scientific and complete; whether the various sub-systems are sound; whether performance evaluation standards are reasonable .

\section{EMPIRICAL RESEARCH}

In order to verify the feasibility of new railway grass-roots unit performance appraisal system, Z Railway Bureau has been applied in practice, and the system construction is divided into four processes. The results are as follows.

\section{A. Establishment Of The Performance Indicator System}

Evaluation index system formed by tree diagram analysis method to decompose railway bureau's demand. According to the commonality, availability or characteristics of indicators and other attributes, all the indicators are divided into three categories: common assessment indicators, professional assessment indicators, and fundamental management indicators. The scores of indicators are set by importance degree of the assessment indicators involved in each grass-roots unit, and the total score is 100 points, as shown in Table 1.

\section{TABLE I.}

WEIGHTS OF PERFORMANCE APPRAISAL INDICATORS OF A UNIT OF Z RAILWAY BUREAU

\begin{tabular}{|c|c|c|}
\hline Project & Indicator & Basic score \\
\hline \multirow{13}{*}{ Public indicators(30) } & Railway traffic safety & 0 \\
\hline & Asset security & 0 \\
\hline & Food safety & 0 \\
\hline & Other security & 0 \\
\hline & Right to pay & 0 \\
\hline & Operating income & 6 \\
\hline & Business comprehensive benefits & 6 \\
\hline & Comprehensive energy consumption & 2 \\
\hline & Non-transportation enterprise income & 6 \\
\hline & Non-transportation enterprise profit & 6 \\
\hline & Collecting income & 2 \\
\hline & Set profit & 2 \\
\hline & Daily average car & 8 \\
\hline \multirow{4}{*}{ Professional indicators(40) } & Total transportation revenue & 10 \\
\hline & Send tons of income & 3 \\
\hline & Cargo delivery & 7 \\
\hline & In the truck & 6 \\
\hline \multirow{3}{*}{ Basic work(30) } & Truck stop & 6 \\
\hline & Work in Finance, labor, statistics & 30 \\
\hline & Total & 100 \\
\hline
\end{tabular}

\section{B. Performance Implementation And Monitoring}

The specific implementation of the process dynamic control mechanism:

First, to analyze performance information, to reduce labor costs and achieve data sharing, $\mathrm{Z}$ road bureau has developed the business performance appraisal information system. Responsible departments must $\log$ in to the performance appraisal information system monthly, and fill in the relevant data.
Second, the evaluation team conducts process control and dynamic analysis of every indicator, and conducts monthly statistical analysis of assessment data.

Fourth, evaluation team organizes responsible departments to inspect the implementation of performance appraisal every six months, find out the problems and loopholes in actual implementation process, and guide and urge all units to carry out rectification in a timely manner. 


\section{Performance Evaluation}

$\mathrm{Z}$ Road Bureau uses three assessment criteria for the performance evaluation of the grassroots units: one-vote veto, quantitative assessment, and qualitative assessment.

One-vote veto on serious issues, for example: serious responsibility traffic, safety, engineering quality accidents, responsible fires, explosions, serious poisoning accidents, serious violations of transportation revenue discipline and other serious violations.

Quantitative assessment of quantifiable indicators has various situation. Aiming at common indicators and professional indicators that include railway transportation, transportation food, personal safety, Z Road Bureau adopts uncontrolled deduction. For example, responsible passenger cars are generally Class $\mathrm{C}$ accidents, each deducting 20 points. According to the characteristics of the indicator, it is divided into two methods which show in Formula 1 and 2, Formula 1 used by calculating absolute quantity, Formula 2 used by calculating relative quantity. For the convenience of description, word A represents actual value, $\mathrm{T}$ represents target value, $\mathrm{B}$ represents basic score, $\mathrm{T}$ represent total score, $\mathrm{C}$ represents assessment criteria score.

$$
\begin{gathered}
\mathrm{T}=\mathrm{B}-[\mathrm{A}-\mathrm{T}] * \mathrm{C} \\
\mathrm{T}=\mathrm{B}+[(\mathrm{A}-\mathrm{T}) / \mathrm{T} * 100 \%]
\end{gathered}
$$

Qualitative assessment services in some indicators that are difficult to quantify, such as deducting 2 points for inadequate implementation of the system.

As a result, performance evaluation criteria should be set to get the final conclusion, If the final conclusion is a one-vote veto or total score is less than 60 that are failing; if the final score is 60 to 75 that is passing; if total score is 75 to 90 that is good, and above 90 is excellent.

\section{Performance Improvement Measures}

Since the implementation of the new performance appraisal system, the management level of the grassroots units has been significantly improved, mainly in the following aspects.

In terms of performance appraisal system construction, all units have formulated corresponding management performance appraisal methods; improved safety management rules and regulations; implied comprehensive budget management in every aspect of management work, revised and improved the financial system and methods; paid attention to the role of safeguarding supervision of democratic management and maximized the right to know the workers; paid attention to TQM that are used to solve problems of safety production, equipment maintenance, income increase and expenditure, and management.

In terms of performance appraisal system itself, it has guaranteed continuous improvement. The monthly inspection work will be conducted to complete assessment indicators of the road bureau or the grassroots units effectively. And the leaders guided and urged the implementation of the rectification personally, then proposed that all units should constantly improve the performance evaluation indicators system, emphasize process management and strengthen the dynamic control mechanism.

\section{E. Assessment Effect Analysis}

Using the radar chart in the common statistical methods of total quality management, comparing before and after the improvement of the $\mathrm{Z}$ Road Bureau, we can see the obvious results, see Table 4 and Figure 1. The numbers 1-5 indicate the level of effectiveness achieved in the assessment organization system, and the effect of 1-5 is increasing.

TABLE II. COMPARISON BEFORE AND AFTER EVALUATION

\begin{tabular}{ccc}
\hline Evaluation content & before & After \\
\hline Assessment system & 3 & 5 \\
Incentive and restraint mechanism & 2 & 4 \\
completion of the mission & 3 & 5 \\
Management effectiveness & 2 & 4 \\
Management behavior & 2 & 4 \\
\hline
\end{tabular}

\section{SUMMARY}

This paper analyzed the inadequacies of the existing performance assessment system for railway grass-roots units, applied the modern enterprise performance management theory, introduced the concept and method of TQM, and followed PDCA to divide the assessment process into four stages: performance plan, performance implementation, performance evaluation, performance application, respectively, constructed the assessment index system, monitoring sub-system, the evaluation sub-system, improvement sub-system. In the design process, it fully embodied the concept of "three whole and one variety" of TQM. The policy management was selected as the theory of goal decomposition, tree map decomposition was used to set assessment indicators. Setting evaluation criteria in accordance with SMART principles and building a new performance evaluation system for railway grassroots units. The establishment of the new system provides reference for the promotion of performance evaluation of grass-roots units, and has brought guiding significance and promotion value in railway bureau.

\section{REFERENCES}

[1] Zou Jun. Construction of Comprehensive Performance Appraisal System in Colleges and Universities [J]. Educational Theory \& Practice, 2015, 35(36):12-14.

[2] Zhang Enfu, Design and implementation of performance appraisal system for railway base stations [D]. Shanghai Jiaotong University, 2012.

[3] Yang Linyan, Zhan Lianke. Analysis of Total Quality Management Theory in China's Public Sector [J].Science of Science and Management, 2006(06):120-125.

[4] Chen Shugong. The enlightenment of $6 \sigma$ management to "three complete and one diversity" [J]. Industrial Technology and Economy, 2003 (05): 23-25.

[5] Anupama Prashar. Adopting PDCA (Plan-Do-Check-Act) cycle for energy optimization in energy-intensive SMEs [J]. Journal of Cleaner Production, 2017,145.

[6] Li Ziqing. SMART Principles and Its Relationship with Performance Management [J]. Market Modernization, 2007(19):148-149. 